\title{
GARABATOS EN UN STORY BOARD: LOS PRIMEROS PASOS PARA COMPRENDER LA NARRATIVA AUDIOVISUAL
}

\author{
Scrawls for a story board: the first steps in understanding the audiovisual \\ narrative \\ Jacqueline Sánchez Carrero (Universidad de Sevilla) \\ http://dx.doi.org/10.12795/AdMIRA.2009.01.05
}

\section{Resumen.}

Existe un campo que colinda entre la educación y la comunicación y que está tomando forma propia desde hace ya algunos años, es la alfabetización audiovisual destinada a niños y adolescentes. El siguiente artículo muestra un retrato de cómo los más pequeños pueden desarrollar sus capacidades para construir mensajes audiovisuales con una lógica narrativa. Una selección de varios ejemplos, producto de talleres de alfabetización audiovisual infantil, sirven de modelo para dar a conocer la práctica del formato gráfico del Story Board. Se trata de una forma atractiva de hacer comprensibles los fundamentos básicos de la narrativa audiovisual a chicos a partir de los 7 años de edad. Sus primeros garabatos van esquematizando ideas, a menudo creativas, en cada cuadro de un Story Board que ha sido ideado por ellos mismos.

\begin{abstract}
There is an audiovisual field which borders on between education and communication and that it is already taking its own form for many years: it is audovisual media literacy intended for children and teenageers. This article shows a picture of how the younger can develop their abilities to construct audiovisual messages with a narrative logic. A selection of several examples, product of children's audiovisual workshops, serves as a model to make known the practice of the Story Board graphical format. It is an attractive way to make the basic foundations of audiovisual narrative understandable to children from the age of 8 . Their first scrawls outline ideas, often creatives, in each picture of a Story Board that has been devised by themselves.
\end{abstract}

Palabras claves: Story Board, educación en medios, guión, narrativa audiovisual, niños, adolescentes.

Keyboards: Story Board, media literacy, script, audiovisual narrative, children, teenageer. 
En las últimas décadas se ha venido acrecentando la presencia de tecnologías audiovisuales casi minimalistas. Áreas como la fotografía o el vídeo se han beneficiado del software y del diseño de equipos que han simplificado su manejo, facilitando tareas como la captación de la imagen fija o en movimiento y el posterior tratamiento informático, para dar como producto final fotografías y películas de corta duración muchas veces de manufactura infantil y juvenil. Sin embargo, -aunque importante- no es suficiente el hecho de contar con la cámara o el equipo editor adecuado y accesible al usuario. Es necesario comprender cómo se otorga sentido a la concatenación de las imágenes que vienen a la mente sobre todo cuando es uno mismo el creador de la historia.

\section{Experiencias formadoras de Pequeños Directores}

En esta década se están dando a conocer experiencias que han puesto su punto de atención en la alfabetización audiovisual de niños y adolescentes alrededor del mundo. Aunque aquí sólo se mencionan algunas de ellas, hay que subrayar que existe un notorio interés por el tema que ha desembocado en la creación de escuelas y talleres audiovisuales. Muchos de ellos ya se pueden considerar veteranos en este tipo de enseñanza pues tienen su origen en la década de los ochenta, antes de que la digitalización hiciera su entrada al gran mercado audiovisual. ${ }^{1}$ Tal es el caso del Taller El Mate en Argentina o la Asociación de cine para Niños y Niñas La Matatena en México, en ambos se lleva a cabo la formación a través de módulos de enseñanza cinematográfica, utilizando distintas técnicas que van desde la animación cuadro a cuadro hasta la edición digital. En otros países latinoamericanos abundan las experiencias aisladas a las cuales se suma un componente diferenciador de tinte regional. En Venezuela por ejemplo, la Cinemateca Nacional puso en manos de los niños de escasos recursos toda una iniciativa audiovisual por demás ambiciosa. En diciembre de 2006 los alumnos de la Escuela Julio César Parra (Coro, Estado Falcón) produjeron durante casi un año un cortometraje llamado Nuestro Miranda, una

\footnotetext{
${ }^{1}$ En Pequeños directores: niños y adolescentes creadores de cine, vídeo y televisión (Aconcagua, 2008), de esta misma autora, se hace un recorrido histórico del panorama de la producción audiovisual infantil.
} 
referencia histórica directa al prócer de la independencia de ese país. ${ }^{2}$ Otros ejemplos que despuntan en el ámbito del aprendizaje audiovisual en el panorama internacional son Orson the kid Escuela de Cine para Niños en Madrid, que trabaja profesionalmente con los niños y jóvenes produciendo cortos y largometrajes, y el Youth and Media. Media Literacy Workshops, un taller que ha funcionado en escuelas neoyorkinas y que emite los mejores reportajes realizados por niños y adolescentes en un programa llamado US Media de la cadena televisiva de servicio público WNYE-Channel 25. Su precursor, Jordi Torrent, está hoy al frente del Programa de Alfabetización Mediática de las Naciones Unidas (Alianza de las Civilizaciones, Nueva York).

Mientras tanto otro grupo de aportaciones ha surgido no a través de academias ni de talleres sino de proyectos apegados al sistema educativo. Un caso modelo puesto en marcha en el 2004 es el Programa Escuela y Medios, implementado por el Ministerio de Educación de Argentina. A través de la enseñanza de apartados específicos con atractivos títulos como Haciendo foco, Escuela, cámara... acción, o La Escuela hace $T V$, los pequeños se familiarizan con toda una gama de conceptos y experiencias acerca del cine y la televisión. Otra muestra no menos notable es el programa Detrás de la cámara, una iniciativa que se lleva a cabo desde hace más de 10 años en La Casa de la Cultura Larrotxene en San Sebastián, al norte de España. En él los niños aprenden a estudiar la imagen y a partir de ello construir historias.

Si desviamos la mirada hacia Internet observaremos que cada vez más están aflorando actividades de construcción del mensaje audiovisual no sólo dirigidas al usuario adulto sino también a los más pequeños. No es extraño descubrir portales donde los chicos pueden, además de visualizar fotografías y reproducir vídeos, mostrar sus propias composiciones audiovisuales. En España el Proyecto Grimm nació precisamente con esa vocación educativa y logró «colgar en la red» micro-reportajes realizados por los alumnos de secundaria de los colegios integrados en el proyecto. Ya para finales del 2007 surgió del ciberespacio un canal de televisión originado gracias a la investigación universitaria. Se trata de Teleclip una televisión bajo demanda por Internet destinada a niños y adolescentes con edades entre 7 y 16 años. En este caso han sido la Universidad

\footnotetext{
${ }^{2}$ Experiencia dirigida por Norma Courlaender y el cineasta Jean Charles L’Ami. Véase «El juego mágico. Construyendo el cine venezolano», Todos Adentro. Semanario cultural de la República Bolivariana de Venezuela, 23 de diciembre de 2006, p. 21
} 
Complutense de Madrid y la de La Coruña las pioneras de este tipo de canales en España, hecho «por y para niños» de toda Iberoamérica. Aunque en una primera etapa pusieron el énfasis en que los chicos se encargaran únicamente de redactar y presentar contenidos, posteriormente consideraron la posibilidad de que pudieran publicar en el portal creaciones de inspiración propia. De este modo los pequeños directores envían sus propuestas ya editadas o simplemente grabadas, en cuyo caso son montadas por los responsables del proyecto quienes posteriormente los integran a la red.

\section{EI Story Board Infantil: comenzando a pensar en imágenes}

Cuando los niños crean pueden desarrollar ideas muy personales y novedosas. El Story Board Infantil es aquel que ha sido diseñado y creado por la mano de un niño o grupos de niños y que está inspirado en ideas propias. Se trata de una magnífica herramienta para lograr que los más pequeños entiendan los fundamentos básicos de la construcción del mensaje audiovisual de una manera esquemática y creativa. Recordemos que el Story Board no es más que una serie de viñetas que muestran los principales planos como eslabones de una historia determinada. Si se sigue paso a paso la elaboración de un Story, como se le suele llamar, se entenderá que hemos de tener conocimiento previo de ciertos aspectos antes de abordar el hecho mismo de dibujar las escenas más importantes. Fundamentalmente se debe conocer la taxonomía de planos; entender qué tipo de planos y movimientos se pueden captar con una cámara de vídeo; reconocer las diferencias existentes entre toma, plano, escena y secuencia; saber qué es una sinopsis y cómo se construye; qué diferencia al tema del argumento, etc. El objetivo al utilizar un Story Board en la alfabetización audiovisual infantil es que, mediante el diseño de ilustraciones secuenciales, el niño comprenda cómo se compone la narrativa audiovisual y pueda argumentar las decisiones que ha tenido que asumir como creador/director de su propia producción.

La edad en que los chicos son capaces de conformar una idea secuencial de una historia determinada suele estar alrededor de los 8 años. Los niños en el nivel preescolar tienen capacidad para distinguir las distintas partes de un cuento infantil tradicional, si les ayudamos en el proceso. No obstante, no es sino unos años después, alrededor de los 8 aproximadamente cuando pueden ordenar una secuencialidad y comenzar a practicar 
con más atino los planos de cámara, comprender su utilización, y consecuentemente, bosquejar sus primeros esquemas de Story Board. De las experiencias que hemos podido realizar en este campo, desde ya hace varios años, se puede afirmar que lo más recomendable es comenzar por la realización de guiones cortos como por ejemplo los publicitarios. Los anuncios destinados a la televisión se prestan perfectamente para que los niños los desestructuren, analicen y, como beneficio añadido, aprendan acerca de un tema tan trascedente como es el comportamiento consumista. Naturalmente, hemos de saber escoger estratégicamente los anuncios que cuenten con la estética y el contenido idóneos según las edades. El spot publicitario cuenta además -sobre todo en los últimos tiempos-, con un amplio abanico de formatos que van desde la óptica tradicional presentando directamente las ventajas del producto- hasta otras formas menos cotidianas, como los centrados en las sensaciones, los de ficción seriados o aquellos de tipo vídeo clip, donde la fragmentación visual se implanta. Por otra parte, en el caso de los guiones propiamente de ficción el Story facilita al formador la fase explicativa sobre la redacción y elaboración del guión literario y del guión técnico. En general, a los niños les resulta atractiva la idea de dibujar una serie de viñetas debido a que lo relacionan, naturalmente, con el cómic o tebeo que es un formato mucho más cercano a ellos.

A continuación se presentan algunos ejemplos de Story Board realizados por niños entre 7 y 11 años producto de distinto talleres que hemos tenido la oportunidad de dirigir. A los grupos se les solicitó que escogieran un producto determinado y que idearan un Story para un spot de televisión. Estos fueron los resultados. Se transcribe el manuscrito del niño al lado cada cuadrante. 


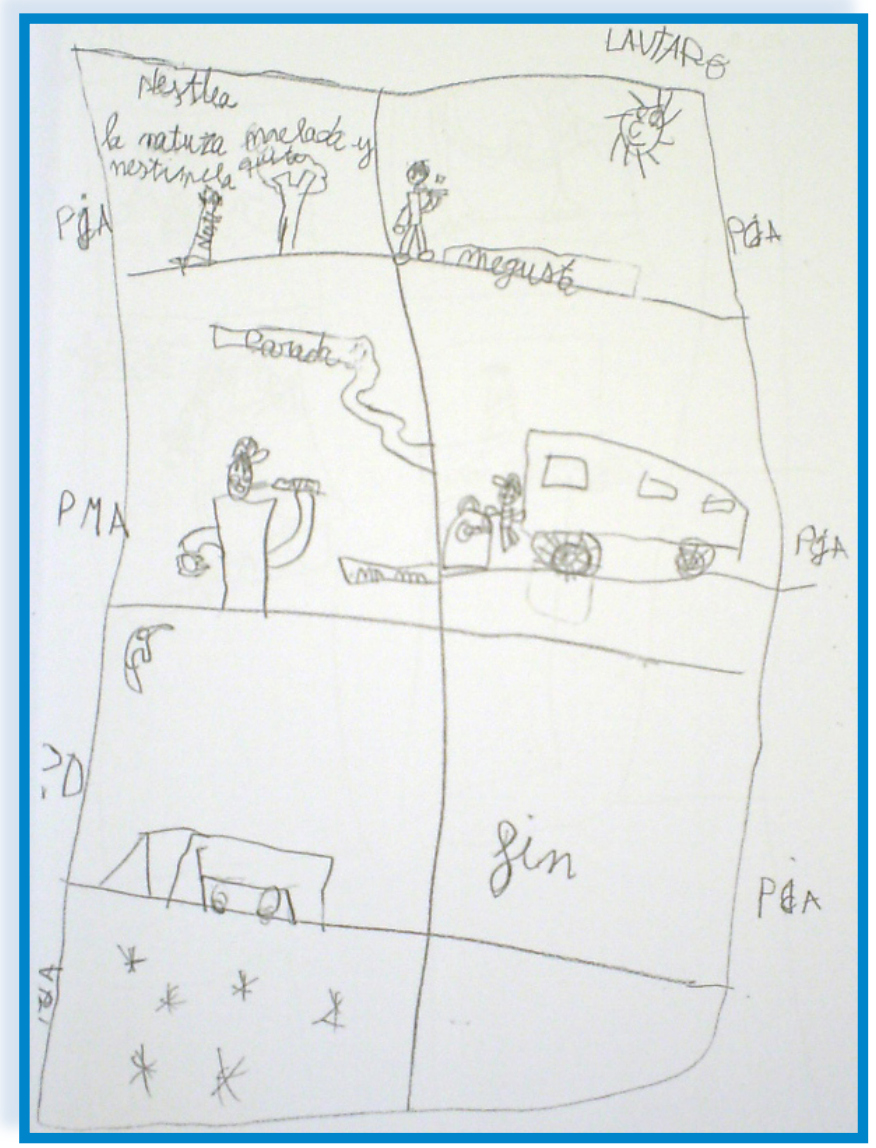

Creador: Lautaro. 7 años.

1.- P.G.A. (Plano General Abierto).

Rótulo: "La naturaleza te la da y Nestea te la quita"

2.- P.G.A. "Me gusta". Un hombre bajo el sol.

3.- P.M.A. (Plano Medio Abierto. "Mmm...". Cerca de una parada de autobús un hombre disfruta de la bebida.

4.- P.G.A. El hombre sube al autobús.

5.- P.D. (Plano Detalle). Se ve unos ojos mirando al cielo y la luna.

6.- P.G.A. Rótulo: FIN

7. P.G.A. Cielo estrellado.

Creadora: Lola. 8 años.

1.- Rótulo: "Baby". Estrellas que brillan en el fondo.

2.- P.G.A. Un perro se tropieza con un bote de colonia y piensa "¿Qué es esto?".

3.- P.G.A. La chica muestra el envase del producto y el perro se pregunta “QQué está haciendo?”. 4.- P.G.C. la chica se unta la colonia. Voz en off: "Oh". 5.- P.G.C. El perro se dice: "¡Anda, si es una colonia!". 6.- P.A. (Plano Americano). Voz en off: "Mmm, qué bien huele". 7.- P.G.C. Colonia Baby. Rótulo: ¡La colonia de todos! La mejor”.

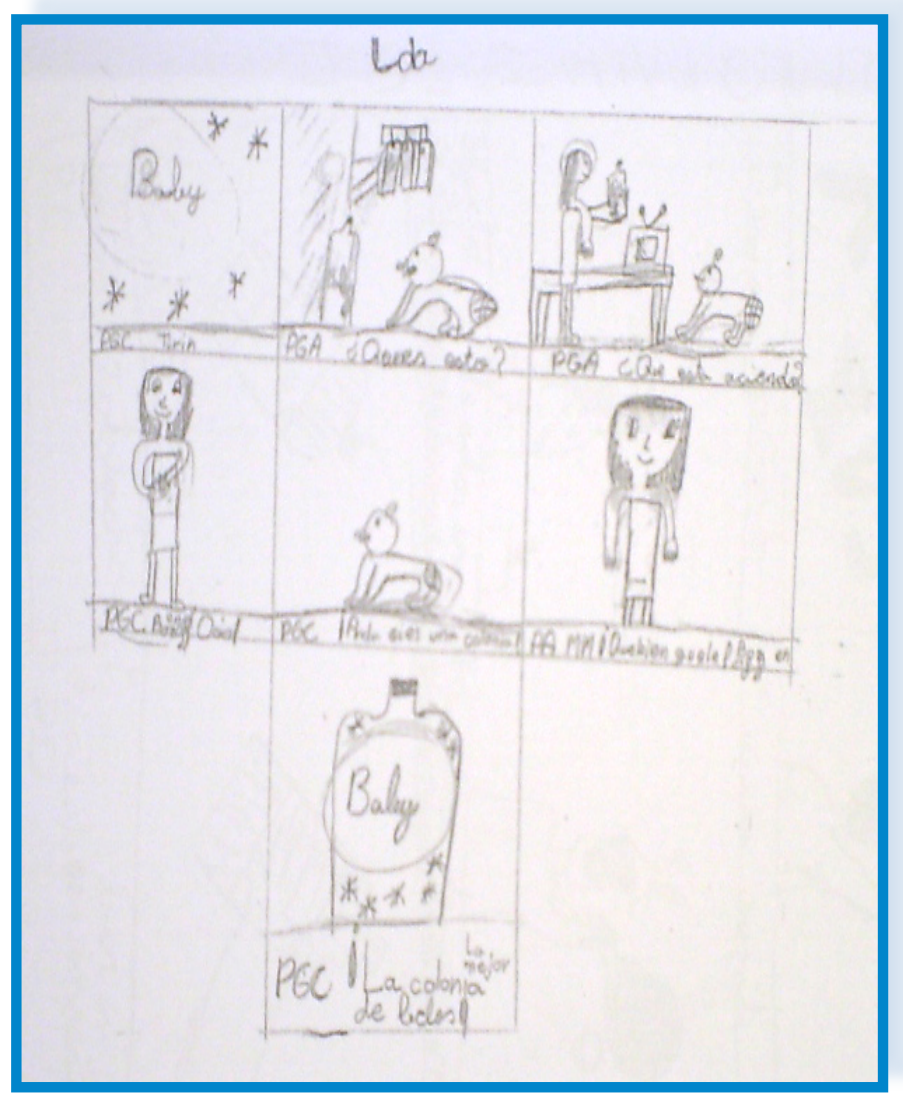




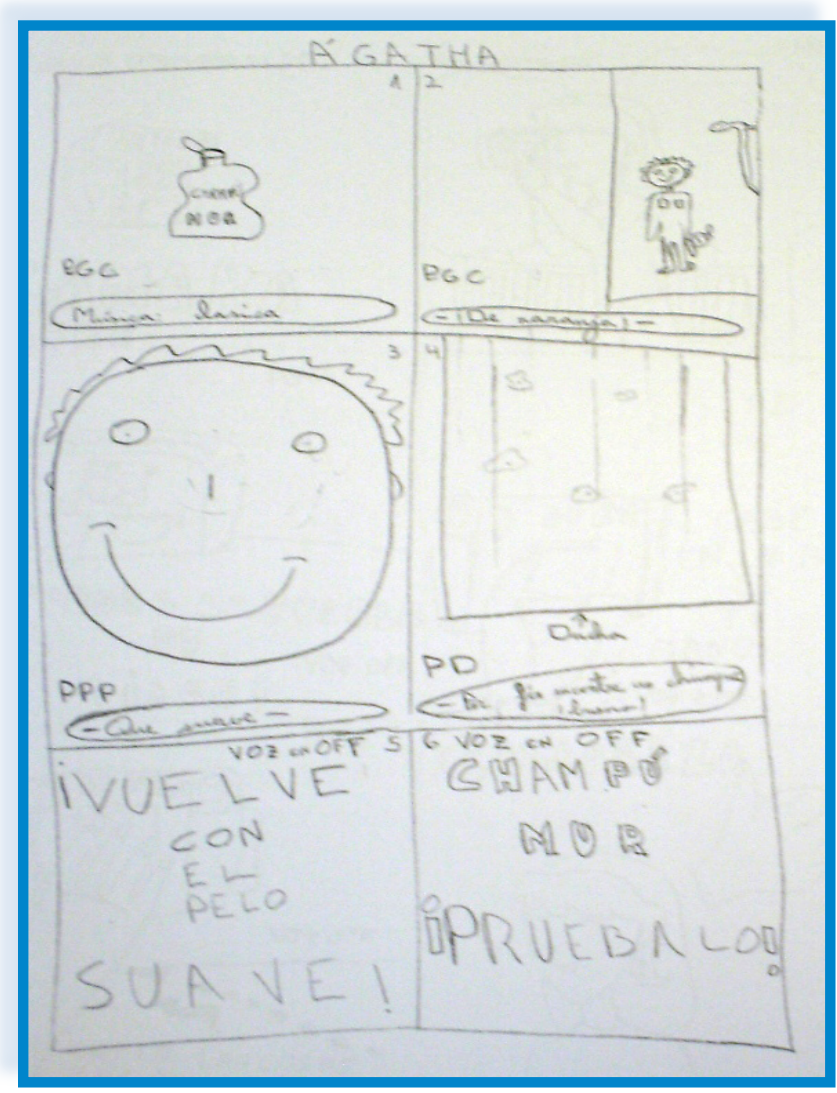

Creadora: Ágatha. 11 años.

1.- P.G.C. Champú Mur. Música clásica.

2.- P.G.C. Una chica en la ducha con el producto en la mano. Dice: "Da confianza".

3.- P.P.P. (Primerísimo Primer Plano) Chica con el producto en el cabello. Dice: "Qué suave..." 4.- P.D. Se ve una parte de la cortina de baño. La chica dice: ¡Por fin encontré un champú bueno!".

5.- Rótulo igual a voz en off: "Vuelve con el pelo suave" 6.- Rótulo igual que voz en off: "Champú Mur ¡Pruébalo!”

Creadora: Ana. 10 años.

1.- P.D. Cámara Luke. Nombre en Rótulo.

2.- P.A. Una chica en un parque utiliza la cámara y dice: “ ¡Es genial!".

3.- P.G.C. Se muestra el producto con un rótulo igual a voz en off. "Puedes llevarla de viaje".

4.- P.D. Se ve la mano con la cámara y una voz en off que dice: "Cabe en la palma de tu mano". 5.- P.D. que muestra la cámara grabando una fila de hormigas. Rótulo igual a voz en off: "Capta las cosas más pequeñas" 6.- Imagen partida con un plano medio de la chica sonriendo una mano en señal de éxito. Rótulo: "Cómprala".

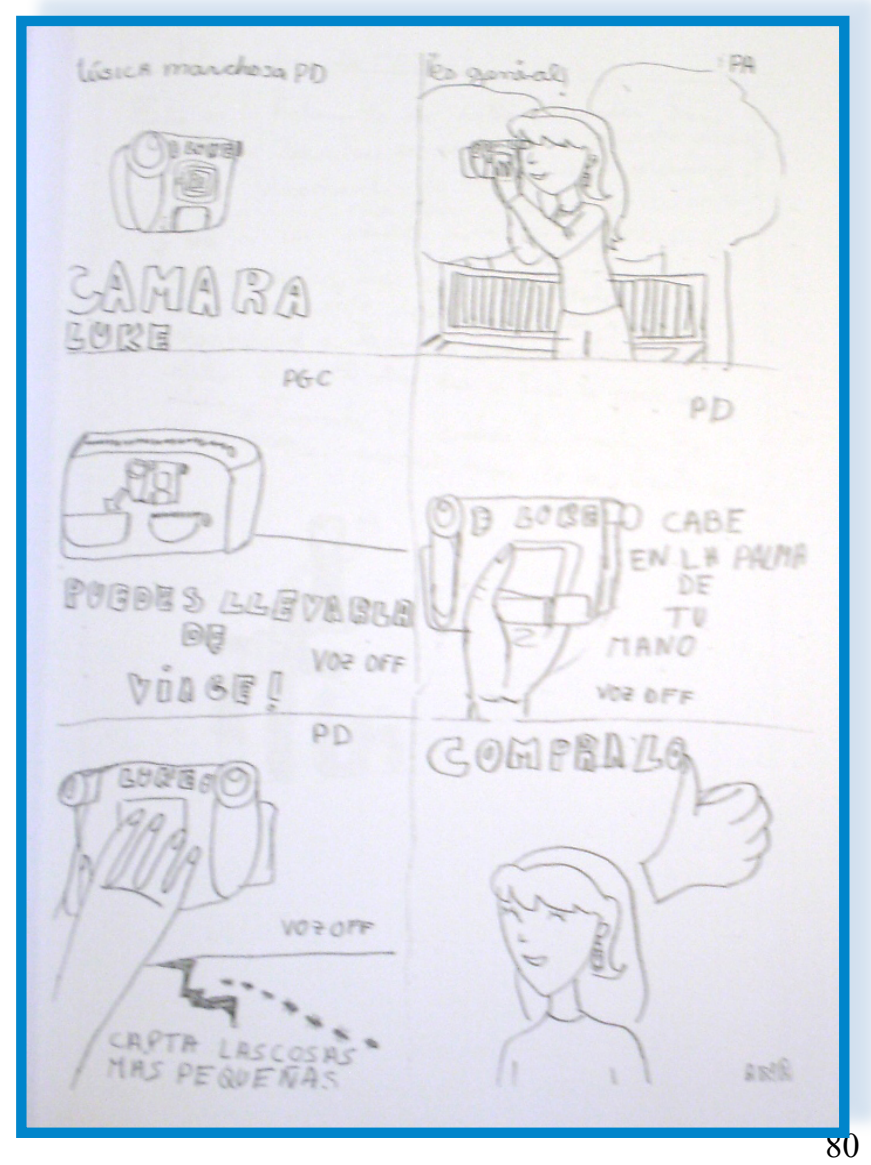

Admira n ${ }^{\circ} .1-2009$ 


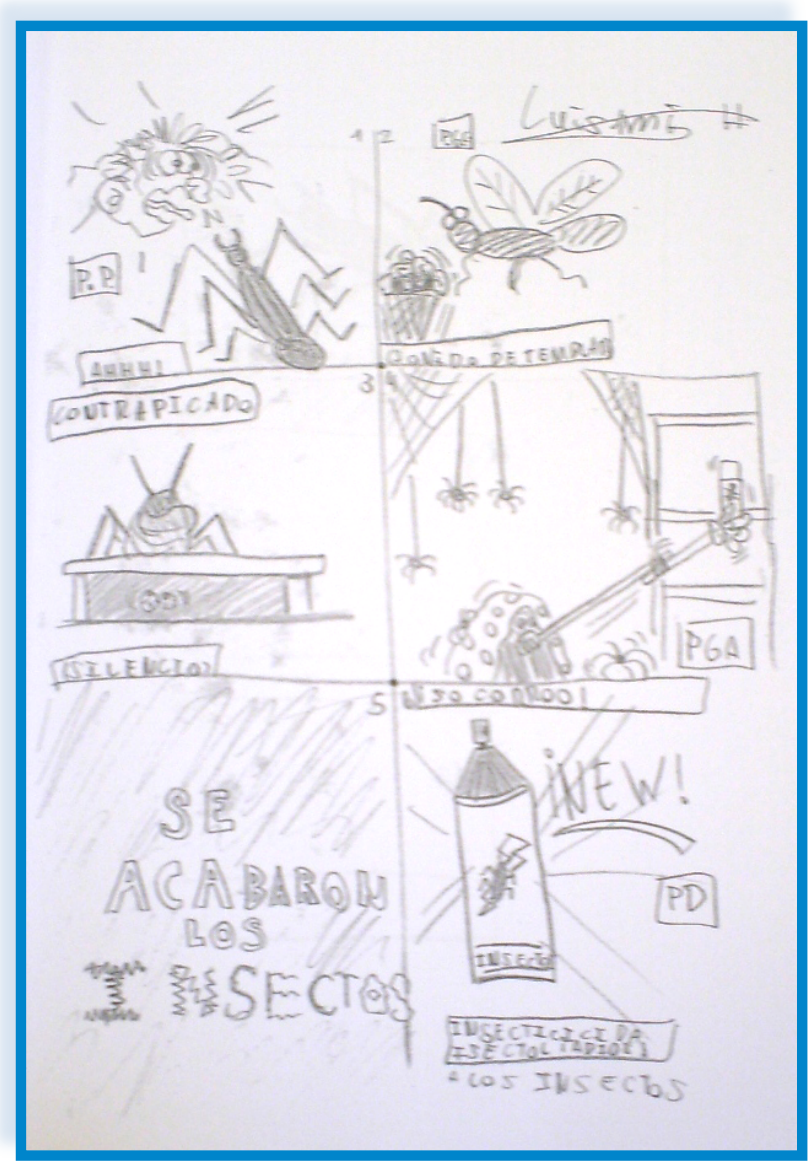

Creador: Luis Miguel. 11 años

1.- P.P. Un hombre asustado grita al ver un insecto muy grande.

2.- P.G.C. Una mosca agigantada se acerca a una cesta de basura.

3.- Plano Contrapicado de un insecto

sobre la mesa de un escritorio. Se ven unos ojos asustados escondido debajo.

4.- P.G.A. El hombre con un palo atado de otro intenta accionar un insecticida mientras las arañas y otros insectos invaden el lugar. 5.- Rótulos: "Se acabaron los insectos".

6.- P.D. del producto. En Rótulos: “¡New! "Insecticida Insectol. ¡Adiós a los insectos!".

\section{Captando la Narrativa Audiovisual}

En las distintas experiencias realizadas con participantes entre 8 y 11 años de edad hemos podido constatar que en general los niños tienen capacidad para desarrollar sus ideas en forma de viñetas sin mayor complicación. Si bien es cierto que los casos presentados tiene pequeñas inexactitudes -tal como el uso consecutivo del mismo tipo de plano- también es verdad que sorprende su forma de plasmar las ideas que tuvieron que crear en muy poco tiempo. Indudablemente el Story es de utilidad al formador a la hora de afrontar diversos aspectos tales como: las partes esenciales del relato planteamiento, nudo y desenlace-, el uso y la intencionalidad de los planos, la 
utilización de recursos como la voz en off, y otros asuntos -pertenecientes al campo publicitario en este caso- como la reason why que muestra los beneficios del producto.

En el debate que prosiguió al diseño del Story sobre la televisión y la publicidad se puedo observar que los niños ya tienen un amplio recorrido de visionado publicitario. Lautaro, a pesar de su corta edad -7 años- tenía muy claro que el mensaje publicitario en ocasiones presentaba hechos en parte irreales. Insistió por ejemplo en contar una anécdota de un amigo suyo cuando pidió por el Día de Reyes un barco pirata sin contar con que la mayoría de elementos se vendían por separado. En su Story tomó el eslogan original de la bebida que recordó fielmente: «la naturaleza te la da y Nestea te la quita», refiriéndose a la sed. Aunque sólo utilizó el plano detalle al final de la historia lo relacionó con el placer de calmar la sed y con un cielo estrellado que también insistió en justificar a la hora de la defensa de su propuesta.

Lola, por su parte, tardó en decidirse por el tipo de producto. Cuando al fin lo consiguió ideó rápidamente la historia relacionándola con las mascotas. Un perro es el «actor»como ella mismo lo definió- que más llama la atención pues es el que consigue el producto, se impresiona ante el envase y percibe la actitud que tiene su dueña cuando lo usa. Intentó enfatizar la imagen del producto más hacia el final del spot con un primer plano y no uno general cerrado, tal como indica con su puño y letra. Aún así la historia guarda sentido. El caso de Ágatha, que también escogió un producto de la gama de cuidado personal, es tal vez el más sencillo de todos. Esta chica de 11 años solía plantear ideas variopintas a la hora de pensar en la producción, aunque ciertamente más sentadas en la realidad que en la fantasía, como otros compañeros de edades menores. Tal como presenta el Story destaca el producto con el primer plano de la chica en la ducha aunque no enfatiza el aroma a naranja que era para ella uno de los principales atributos diferenciadores.

En el caso de Ana, de 10 años, observamos a una niña con pensamiento organizado tanto en el planteamiento de la idea como en la resolución ilustrativa. Se trata de una chica inteligente y hábil que captó rápidamente de qué trataba la actividad y qué era lo que quería transmitir. Eligió estratégicamente un objeto que tuviera que ver con el mundo audiovisual y luego se dedicó a pensar la forma de anunciarlo por televisión. Su 
principal acierto reside en destacar las ventajas del producto que comentó a sus compañeros de esta manera: «Es de tamaño accesible a la palma de una mano, captura detalles tan pequeños como una fila de hormiguitas, es ideal para llevar de viaje».

Por último, el planteamiento de Luis Miguel, es uno de los más claros y trabajados. Si bien es cierto que el chico tiene facilidad para el dibujo, posee además lo que se denomina «mirada de cámara». Si observamos los planos número 3 y 4 podemos notar la ubicación que da al protagonista de la acción. En el primer caso lo sitúa escondido debajo de la mesa de escritorio captado con un plano contrapicado, y en el segundo, oculto bajo una sábana mientras intenta accionar el producto. Pensó igualmente en destacar el insecticida en el cuadro final con el vocablo inglés «new» y con unos haces de luz que destellan enmarcándolo.

En la narrativa audiovisual cuenta toda una gama de aspectos que dan vida y razón al propio mundo de la imagen y el sonido. El niño puede distinguir el relato audiovisual no sólo en el cine y en la televisión sino también en los videojuegos, en las animaciones de pequeño formato -muy en uso en la telefonía móvil- o en cualquier expresión con imagen y sonido de las nuevas pantallas interactivas. Educar en la imagen y el sonido cobra importancia hoy más que nunca, ya no se trata de un conocimiento limitado al alumnado de niveles superiores. Compartimos el pensamiento de Fernández Díez cuando afirma: «Desde el punto de vista del lenguaje y la narrativa audiovisual alfabetizarse quiere decir aprender las reglas, como mínimo las básicas. La finalidad es la de construir un sistema que facilite el aprendizaje para identificar, comprender y crear mensajes audiovisuales. (...) La narrativa, y especialmente los aspectos formales del lenguaje audiovisual son, como cualquier otra técnica comunicativa, susceptibles de aprendizaje» (Fernández Díez, 2001: 15).

Otros aspectos de competencia audiovisual en la enseñanza de la narrativa a los más pequeños abarcan el campo de la continuidad, la puesta en escena y el montaje o edición. Ésta última fase supone para ellos un universo mágico debido a que pueden «jugar» con los clips de imagen y sonido. No obstante, en el diseño del Story Board los niños encuentran un gran espacio para esparcir su creatividad con apenas lápiz y papel, sobre todo si les dejamos libertad para escoger la temática ya sea de un anuncio 
publicitario o de un guión de ficción. Por otra parte, no debemos olvidar que la narrativa audiovisual publicitaria tiene su propio objeto de estudio, razón por la cual guarda ciertas disimilitudes a la hora de compararla con otros escenarios. La narrativa audiovisual publicitaria investiga «las manifestaciones audiovisuales, tanto lineales como interactivas, orientadas a la presentación, promoción, venta y/o concienciación de ideas, bienes y servicios costeados por personas, empresas o instituciones» (Moreno, 2003: 31). Y es que la publicidad enfoca sobre todo la persuasión, un enfoque discursivo no del todo incomprensible por los más pequeños: «Los niños y niñas aprenden a reconocer e interpretar los dispositivos retóricos específicos de los medios que presentan imágenes en movimiento. Es un hecho importante, porque se indica un proceso de aprendizaje sobre un sistema retórico que está jugando un papel significativo en nuestra cultura». ${ }^{3}$ Aunque la publicidad se preste magistralmente para la enseñanza de la narrativa audiovisual a niños y adolescentes hemos de tener en cuenta que se trata de una disciplina heredada de otra más amplia. Con ella guarda diferencias pero se asemeja en los temas generales que son los que en última instancia nos interesan en esas primeras fases de aplicación de la enseñanza audiovisual.

El uso del Story Board se nos presenta como una dinámica educativa de fácil acceso y entendimiento. Basta con dibujar en un folio el formato típico de cómic con varios cuadrantes, o si se prefiere, el formato clásico de dos columnas, una -la de la izquierdadestinada a la imagen y otra -a la derecha- para el sonido. Luego animar al niño a jugar con su imaginación y componer pequeñas historias. El hecho de organizar las imágenes en secuencia le ayudará a encadenar la idea principal del mensaje utilizando la lógica, mientras que la selección de planos y de sonidos aportará el sentido final de la situación creada que ha de ser entendidas por todos.

\footnotetext{
${ }^{3}$ Entrevista realizada a Cary Bazalgette a propósito del Foro Mundial de la TV Infantil efectuado en Barcelona en noviembre de 2008.
} 


\section{Referencias bibliográficas}

Bazalgette, C. (2008): «Cary Bazalgette. British Film Institute (BFI) 1979-2007» en

Revista Anual Paideia TV La Ciudadanía Comunicativa, nº 10, Barcelona, p. 22.

Fernández Díez, F. (2001): Manual básico de lenguaje y narrativa, Barcelona, Paidós.

Ganci, Z. (2006): «El juego mágico. Construyendo el cine venezolano» en Todos

Adentro. Semanario Cultural de la República Bolivariana de Venezuela, Caracas, p. 21.

Moreno, I. (2003): Narrativa audiovisual Publicitaria, Barcelona, Paidós.

Sánchez Carrero, J. (2008): Pequeños directores: niños y adolescentes creadores de cine, vídeo y televisión, Sevilla, Aconcagua. 